\title{
47 ANOS DE FEIRA DO SOM E A RECONFIGURAÇÃO DA NARRATIVA MUSICAL: produção de sentidos na Rádio Cultura Pará
}

\author{
47 YEARS OF FEIRA DO SOM AND THE MUSICAL NARRATIVE \\ RECONFIGURATION: production of meanings at Rádio Cultura Pará
}

\author{
Jússia Carvalho da Silva VENTURA ${ }^{1}$ \\ Lídia Karolina de Sousa RODARTE² \\ Alda Cristina Silva da COSTA ${ }^{3}$ \\ Universidade Federal do Pará | Brasil
}

\begin{abstract}
Resumo
A tessitura deste artigo parte da cenarização da linguagem radiofônica na ressignificação dos sentidos, memória e experiência social, tendo como corpus de análise o programa Feira do Som da Rádio Cultura. Indagamos sobre como um programa, configurado entre jornalismo musical e cultural, se mantém no ar por 47 anos, com o mesmo modelo e formato, construindo sentidos para o público. Partimos da "conversão semiótica" (LOUREIRO, 2017) e da síntese do heterogêneo na narrativa (RICOEUR, 2010) para concluir que o programa compartilha sentidos que possuem os mesmos referenciais simbólicos, refletidos na linguagem, que partilha com os ouvintes os mesmos signos.

Palavras-chave

Programa Feira do Som; Conversão semiótica; História do rádio; Rádio Cultura; Narrativas.

\section{Abstract}

The composition of this article comes from the scenarization of the radiophonic language in the reframing of the senses, memory and social experience, having as a parsing corpus the program Feira do Som from Radio Cultura do Pará. Our inquiry is on how a program, configured between musical and cultural journalism, maintains it self for 47 years, with the same model and format, and continuously creates meanings to the public. from the "semiotic conversion"(LOUREIRO, 2017) and the synthesis of the heterogeneous narrative (RICOEUR, 2010) to conclude that the program shares meanings with the same symbolic references, reflecting on the language, which shares with the listeners the same signs.

Keywords

Feira do Som Program; Semiotic Conversion; History of radio; Amazon Radio; Narrative.
\end{abstract}

\section{RECEBIDO EM 24 DE MARÇO DE 2020}

ACEITO EM 27 DE MAIO DE 2020

\footnotetext{
${ }^{1}$ Doutoranda do Curso de Pós-Graduação em Sociologia e Antropologia, da Universidade Federal do Pará, Mestra em Ciências da Comunicação pelo Programa de Pós-Graduação, Cultura e Amazônia (UFPA/PA). Contato: jussiac@gmail.com.

2 Doutoranda do Curso de Pós-Graduação, Cultura e Amazônia da Universidade Federal do Pará (UFPA). Integrante do Grupo de Pesquisa Narrativas Contemporâneas na Amazônia Paraense (NARRAMAZÔNIA). Contato: lidiakarolina@gmail.com.

3 Doutora em Ciências Sociais (UFPA/PA). Docente FACOM/PPGCOM (UFPA/PA). Coordenadora dos Projetos de Pesquisa Mídia e Violência: narrativas midiáticas na Amazônia Paraense e Narrativas Contemporâneas na Amazônia Paraense (NARRAMAZÔNIA). Contato: aldacristinacosta@gmail.
}

João Pessoa - Brasil | ANO 7 VOL.7 N.1 | JAN./JUN. 2020 | p. 454-473 454 Revista Latino-americana de Jornalismo | ISSN 2359-375X Programa de Pós-Graduação em Jornalismo - UFPB 


\section{ANECRA}

Jússia VENTURA - Lídia RODARTE - Alda COSTA

\section{Introdução}

s emissoras de rádio têm buscado se adaptar às transformações
tecnológicas, seja pelos suportes em que estão abrigadas, seja
pelos conteúdos que passam a redimensionar suas programações. Suas realidades são híbridas. Por vezes, existem em espaços tecnológicos diferenciados para atender realidades e públicos diferenciados. No caso da Rádio Cultura do Pará, emissora ligada à Fundação Telecomunicações do Pará (Funtelpa), conhecida como Rede Cultura de Comunicação, sua existência ainda tem caráter FM (frequência modulada), recorrendo apenas às mídias sociais para divulgação.

A Rádio Cultura é uma emissora pública e foi criada em 1977, no auge da ditadura militar. Ainda hoje funciona como principal símbolo da política pública de comunicação do Governo do Estado, reificando, em sua programação diária, a representação da identidade cultural amazônica (CASTRO, 2012). Sua implantação foi um diferencial, pois passou a produzir formatos jornalísticos e musicais que escaparam aos ditames das emissoras comerciais, privilegiando, segundo informações do Portal Cultura ${ }^{4}$, a divulgação e circulação das manifestações artísticas e culturais da região amazônica. Desde o início, a emissora busca a construção da memória social de Belém, ou seja, dos aspectos que demarcam, esteticamente, o espaço do que seria uma cultura amazônica, a partir dos produtos de sua programação diária.

É nesse contexto que escolhemos, para este artigo, trabalhar com a Feira do Som, um dos programas mais antigos da rádio paraense, no ar desde 1972. O programa esteve em três emissoras, duas comerciais e uma pública: na Rádio Clube do Pará (1972-1982), uma das mais antigas emissoras do estado do Pará, com mais de 90 anos de existência; na emissora Cidade

\footnotetext{
${ }^{4}$ Disponível em: <www.portalcultura.com.br/node/470>. Acesso em: 22 jul. 2019.
} 
Morena FM (1982-1984); e, por último, desde 1984 até os dias atuais, está abrigado na Rádio Cultura, primeiro na Onda Tropical e, a partir de 1986, na FM. Nossa intenção é compreender como o programa se organiza para continuar configurando sentidos junto aos ouvintes e como são estabelecidas as relações interativas entre Feira do Som e ouvintes.

Nesse contexto, observamos a dinâmica existente na construção das relações comunicativas entre o programa e os ouvintes, considerando que a comunicação não é uma prática apartada da dinâmica da sociedade, ao contrário, é uma das práticas que dá a ver essa dinâmica e as forças que a impulsionam.

É relevante destacar o papel das emissoras públicas que ainda figuram como um diferencial quando comparadas às emissoras comerciais, pois oferecem produtos com características mais específicas da realidade em que estão inseridas, informações de interesse público e com viés educativo (COSTA; MEDEIROS, 2015), podendo construir possibilidades de gerar intimidade e relação afetiva mais estreita com os ouvintes, mesmo a despeito de algumas críticas, quando identificado o caráter político dado a essas emissoras pelos sucessivos grupos de poder, no caso do Estado do Pará, denominado, segundo Castro (2012), de ethos dominante dos grupos hegemônicos, que se manifesta quando ocorre a apropriação da emissora para atender aos interesses desses grupos.

Como visada teórica e metodológica, recorremos aos estudos de Paes Loureiro e Paul Ricoeur. De Loureiro (2007), cunhamos a discussão sobre a conversão semiótica, entendendo-a como um processo de mudança de função ou de significação dos fatos da cultura, operado a partir da cenarização da linguagem. A conversão semiótica é possibilitada pelo pensamento simbólico, em que a recepção da realidade se dá por meio de significações que se atribuem aos fatos ou eventos. Segundo Loureiro (2007, p. 16), "a conversão 


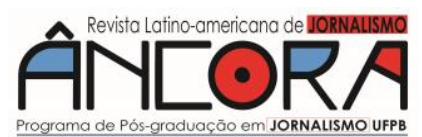

Jússia VENTURA - Lídia RODARTE - Alda COSTA

semiótica resulta em um modo de compreender a realidade de forma dinâmica e concernente ao seu sistema processual de mudanças".

Com Ricoeur (2010), refletimos sobre a narrativa construída por Edgar Augusto, idealizador e locutor da Feira do Som. Por exemplo, quando compomos uma narrativa, nós, na condição de sujeitos narradores, estruturamos tempo e ações subjetivamente. Nesse processo de contar, alguns acontecimentos se destacam, enquanto outros perdem destaque e até desaparecem (COIMBRA, 1993 apud CARVALHO, 2010). Esse processo, ocorre na ficção, mas também nas narrativas factuais, como a histórica e até a jornalística.

O tempo é o elemento central na tessitura da intriga, entendida por Ricoeur (2010) como uma imitação da ação, ou a transferência da ação do mundo da vida quotidiana para o mundo da narrativa. O conceito de ação em Ricoeur (2010) é relevante na análise da Feira do Som, porque diz respeito à coletividade. Segundo o autor, a ação vai sempre em direção ao outro, agir é agir com o outro, em um ciclo que se fecha apenas na interação.

A partir dessa compreensão, fazemos uma abordagem centrada na entrevista em profundidade, com o idealizador/locutor da Feira do Som ${ }^{5}$, assim como uma análise descritiva do programa. A entrevista foi realizada em dois momentos, com intervalo de dois anos: fevereiro de 2017 e julho de 2019, com o objetivo de compreender a lógica de produção e relação com o público. Além disso, ouvimos 23 (vinte e três) edições do programa durante o mês de janeiro de 20186, para interpretar sua composição, e analisamos as expressões, os jargões, a participação do público e os quadros. É importante destacar que a escuta dos programas teve a finalidade de perceber a construção narrativa como um todo, não suas particularidades, ou seja, o que

\footnotetext{
${ }^{5}$ Essa reflexão faz parte do projeto de pesquisa em andamento "A construção da memória social de Belém", que objetiva analisar, a partir do programa Feira do Som, como a memória social de Belém é construída, tendo em vista o público paraense.

${ }^{6}$ As edições fazem parte do acervo do projeto de pesquisa "A construção da memória social de Belém", desenvolvido na Universidade Federal do Pará.
} 
cada dia o programa apresenta, pois a narrativa da Feira é um continuum, sem alterações no seu roteiro. Também usamos como material de apoio, para a construção deste artigo, os vídeos de entrevistas com a produção da Feira disponíveis na plataforma online Youtube?.

\section{Construção da memória social: o caso da Rádio Pública Paraense}

Cada cidade tem uma imagem e identidade próprias, que podem ser percebidas nas sonoridades e que pertencem a um espaço-tempo específicos. O som representa a vida social, podendo trazer consigo imagens simbólicas (DURAND, 2001). Assim, identificamos Belém como uma cidade sonora. Lugar cheio de paisagens que remetem ao poético e afetivo, compostas pelos múltiplos sons que constituem o quotidiano e ajudam a dimensionar a sua memória social. Vivemos essa experiência nas cenas que são comuns no dia a dia da capital paraense: o falatório da feira do Ver-o-Peso, o tecnobrega ou as aparelhagens nas periferias da cidade, os carros de som que rodam pelas ruas anunciando produtos, os festivais de música clássica, os gritos de "lá vem a chuva" e "cuidado com a manga", os incentivos, que saem das caixas de som espalhadas pela cidade, aos romeiros de Nossa Senhora de Nazaré durante o Círio, gritando "Viva Nossa Senhora!" ou entoando os cânticos nas treze procissões e romarias.

Nesse sentido, os sons são elementos que ajudam a compor o cenário da cidade, revelando características culturais das sociabilidades dos belenenses, e as emissoras de rádio têm papel decisivo nessa composição. Assim, a sonoridade constitui-se em componente cultural importante, uma vez que ela expressa as manifestações diárias das pessoas nos seus diferentes afazeres quotidianos.

\footnotetext{
7 Os dois vídeos disponíveis no Youtube com entrevistas e informações sobre a Feira do Som foram utilizados para a construção do artigo: <https://www.youtube.com/watch?v=SzMi-TymF3I\&t=57s> e <https://www.youtube.com/watch?v=CFoGFZX1Kms\&t=98s>
}

João Pessoa - Brasil | ANO 7 VOL.7 N.1 | JAN./JUN. 2020 | p. 454-473 


\section{ANTLORA}

Jússia VENTURA - Lídia RODARTE - Alda COSTA

E é por meio do rádio que Costa (2015) identifica a "mestiçagem cultural" da chamada "Cidade das Mangueiras", nome carinhoso de Belém, pois são incorporados elementos eruditos, folclóricos e massivos, sons e batidas dos mais variados matizes, que simbolizam a rica mistura da história dos seus moradores. Segundo o autor, desde a década de 1950, a rádio paraense tem representado esse rico cenário da diversidade musical na sua programação. A Feira do Som nasceu e apareceu com esta proposta, de ser uma feira que oportuniza uma variedade de músicas de todos os períodos, do clássico ao moderno (PROENÇA, 2019).

O programa, na atualidade, integra uma emissora pública, com viés educativo, sendo uma das maiores da capital paraense e da região amazônica: a Rádio Cultura FM. Antes disso, é importante dizer que a Cultura FM foi precedida pela Rádio Cultura Onda Tropical, que marcou o início da política pública de comunicação do Governo do Pará, num momento em que o discurso de integração da Amazônia se destacava, pois as distâncias geográficas e a falta de infraestrutura dificultavam a fiscalização da vida dos cidadãos (COSTA; MEDEIROS, 2015).

A Cultura FM entrou no ar pela primeira vez em 1985, como uma proposta alternativa às rádios comerciais. Sua grade musical priorizava composições paraenses, do popular ao erudito (COSTA; MEDEIROS, 2015), e tinha como objetivo valorizar a manifestação e produção amazônica, promovendo um jornalismo regional a fim de preservar a 'Identidade Cultural Paraense'.

Lembramos que o contexto da redemocratização do país e a Constituição de $1988^{8}$ contribuíram para o aparecimento de produtos midiáticos preocupados com a participação do público. A programação tinha mais participação e a 'cara' do público local, assim como a valorização dos artistas paraenses. Somado a isso, Belém vivia uma geração que pretendia

\footnotetext{
${ }^{8}$ Considerada uma Constituição Cidadã por representar um marco democrático da garantia das liberdades civis, dos direitos dos brasileiros e dos deveres do Estado.
} 
regionalizar o conteúdo cultural (CASTRO, 2011), que teve seu protagonismo usurpado, tanto nos produtos de mídia tradicional (DUTRA, 2009), quanto nos relatos que remetem ao período colonial, que representavam os sujeitos amazônidas como passivos diante do grande lugar de possibilidades que era a Amazônia (COSTA, 2011).

A proposta da Feira era inovadora, falar sobre produção musical local e configurar sentidos que pudessem ser compartilhados pelo público paraense, dando voz àqueles que eram invisíveis à indústria fonográfica, além de dialogar com ritmos que estavam fora da cena musical de massa. Após vários anos no ar, os jargões, o formato, os quadros e a forma de narrar foram cristalizandose até se tornarem tradicionais. Lembremos o que diz Ricoeur (2010) quando reflete sobre a tradição e inovação, não como polos necessariamente opostos, mas complementares, no sentido de que a tradição seria a inovação sedimentada.

A inovação é fruto da imaginação criadora e produtiva, mas está assentada em modelos e paradigmas tradicionais, dentre os quais está a própria linguagem. Porém, por meio da inovação, propiciada pela imaginação e por uma fuga do padrão, surge o original, a novidade. Edgar Augusto representava, à época do surgimento do programa, um anseio pelo novo, por retratar o que acontecia no universo musical regional que o cercava e que, até então, era invisibilizado e suplantado pelos conteúdos musicais internacionais. A inserção do quadro de interação com o público também adicionou à configuração do programa um caráter inovador, tanto de reforço da narrativa, pela união de vozes diferentes e de novos componentes heterogêneos, quanto de construção de sentido temporal, visto que há uma tentativa de contribuir com a operação de configuração empreendida por Edgar.

O idealizador do programa narra a música em um contexto cultural, histórico e social. As informações são veiculadas levando em consideração as 


\section{ANEORA}

Jússia VENTURA - Lídia RODARTE - Alda COSTA

premissas do jornalismo de apuração e noticiabilidade. Para Proença (2019), o diferencial está na informação detalhada e na relação com o público.

\section{Olá Edgar! Agora é a hora da Feira, da Feira do Som!!}

Nos moldes de um jornal musical, foi na Rádio Clube do Pará, uma rádio AM das mais antigas do país, que a Feira do Som fez sua primeira transmissão, em 1972. A rádio pertencia à família do jornalista Edgar Augusto (PROENÇA, $2017^{9}$ ). As rádios locais, naquele momento, contavam com músicas estrangeiras e especialmente com ritmos latinos (COSTA, 2015).

$O$ objetivo era fazer jornalismo musical para dar visibilidade à produção e aos artistas paraenses (FUNTELPA, 2007). Para isso, o jornalista inspirou-se no programa Pocket Show, apresentado por Rosenildo Franco na Rádio Clube, entre 1968 e 1969 (FUNTELPA, 2007).

Depois da venda da Rádio Clube do Pará, a Feira do Som passou a ser transmitida pela Cidade Morena FM. Lá, ficou pouco tempo, pois a linha editorial era mais jovem e comercial. Com a inauguração da Rádio Cultura FM, a Feira do Som passou a fazer parte da programação aos sábados durante duas horas em 1986 (FUNTELPA, 2007). Em um mês, passou a ser diário e segue até hoje. Pode ser sintonizado de segunda a sexta-feira, de meio-dia a duas horas da tarde, na cidade de Belém e região metropolitana.

O programa é ao vivo e começa com o locutor apresentando uma música inédita na Feira do Som. Edgar Augusto mescla músicas regionais com sons que tocam pelo mundo. São vinte músicas por dia, as quais intercala com comentários sobre a produção e curiosidades gerais. Para o finalzinho, ficam os quadros fixos do programa, quando tocam "músicas antigas, dos tiozões, músicas das décadas de 1960, 1970" (PROENÇA, 2019). O quadro é acompanhado de uma vinheta chamada "horário sagrado dos titios", com um background de fundo. Logo depois segue o quadro no "Cantinho dos

\footnotetext{
${ }^{9}$ Entrevista com Edgar Augusto Proença, idealizador e locutor da Feira do Som, concedida a uma das autoras deste artigo em fevereiro de 2017.
} 
Beatles", com duas músicas do quarteto, que podem ser da carreira solo de um dos integrantes ou interpretações de outros artistas de canções consagradas. Esse quadro surgiu a pedido dos ouvintes, quando o programa passou à Rádio Cultura FM (PROENÇA, 2019). Nesse momento, o locutor se aproxima dos que gostam da música dos Beatles, sendo que muitos dos fãs mais assíduos têm seu nome citado pelo Edgar ao final do quadro. $O$ terceiro quadro é o elo direto com o ouvinte. É por meio das perguntas de Grisalho Couto que o ouvinte interage com a Feira. Depois da primeira música, um questionamento sobre a cidade de Belém é lançado pelo apresentador, oferecendo prêmio a ser sorteado entre as pessoas que acertarem a resposta. As perguntas mexem com a memória do ouvinte. Observamos que esses lugares lembrados ou demarcados pelo locutor são ressignificados entre passado e presente, na medida em que "o pensamento simbólico atribui a fatos da natureza a condição de causa de fenômenos, unifica a pluralidade, no devir de um todo intimamente relacionado com realidade e imaginação" (LOUREIRO, 2007, p. 15). Nas vinte e três edições analisadas, observamos a figura marcante do apresentador, que, por vezes, confunde narrativa e narrador, em que "a identidade do narrador, o grau e a maneira pela qual essa identidade está indicada no texto, e as escolhas que estão implicadas garantem ao texto o seu caráter específico" (BAL, 1985, p. 120).

O quadro mais antigo do programa, "No cantinho dos Beatles", exemplifica como ocorre a construção de uma memória social e afetiva a partir de uma identidade coletiva, pois, para sociabilizar e criar afeto, é preciso lembrar e se sentir pertencente ao grupo, já que a memória enquanto indivíduo é condicionada a padrões coletivos e ao pertencimento em sociedade. Entendemos afetar, aqui, como comover, mexer com sentimentos ou provocar modificação no ser (RIBEIRO, 2013). Somos afetados quando passamos a sentir e a pensar diferente da forma anterior de ter sido afetado, ou, como nos 


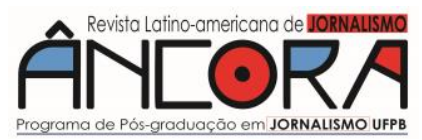

\section{Jússia VENTURA - Lídia RODARTE - Alda COSTA}

diz Paes Loureiro (2007, p. 17), "o homem simboliza onde quer que ele esteja e, com isso, atualiza e enriquece as relações com a realidade".

A priori, aquilo que poderia não fazer sentido para os ouvintes mais jovens, quando o locutor se utiliza quase sempre de uma Belém do passado, é convertido semioticamente para o presente, por ressignificações, com uma mudança de qualidade do signo ou como

\footnotetext{
o movimento de uma passagem pela qual as funções se reordenam e se exprimem em uma outra situação cultural. A mudança de qualidade simbólica em uma relação cultural. Na cultura amazônica, a conversão semiótica para o estético, segundo a qual as funções se reordenam e se exprimem pela formação ressimbolizada e sobre a qual recai a contemplação (LOUREIRO, 1995, p. 39).
}

É a partir desse lugar de sociabilidade e da afetividade que é construída uma memória social de Belém, memória que a Feira do Som ajuda a compor. Além de rememorar a vivência de quem esteve nessa cidade de outrora, aguça a curiosidade de quem vive as mudanças e transições da Belém atual.

Essa configuração de memórias está relacionada às ações sintetizadas na narrativa. Ao pensar na ação, recorremos às mímeses ricoeurianas (RICOEUR, 2010). A primeira delas, e a que nos interessa neste momento, é um componente cultural da ação, ligado aos elementos simbólicos que aprendemos socialmente enquanto vivemos. É a partir dela que concluímos se uma ação é digna de nota ou não. Para um comunicador como Edgar Augusto, essa percepção é imprescindível, pois é necessário perceber os caracteres estruturais, simbólicos e temporais de uma ação, para que ela faça sentido dentro da configuração do programa e, assim, possibilite a seleção daquilo que desperta o interesse de seus ouvintes.

\section{A reconfiguração narrativa da Feira do Som}

O programa Feira do Som passou a fazer parte do quotidiano dos belenenses. São quarenta e sete anos ininterruptos. Sua produção permite perceber a tessitura de laços afetivos entre os ouvintes e o programa, em razão dos próprios interesses estabelecidos entre ambos (sensoriais, ideais, 
conscientes, inconscientes, momentâneos, duradouros etc.), os quais se alinham a uma rede com os mesmos interesses, o que forma a base da sociedade (SIMMEL, 2006).

Nos primeiros anos da Feira, o processo de interação não tinha espaço no programa, pois, segundo Edgar Augusto (PROENÇA, 2019), ele fora pensado como um jornal musical que noticiava a produção do mercado fonográfico da época. Ao selecionar as músicas, era necessário criar uma relação de sentido de sua divulgação, programa e público. Nessa perspectiva, o papel do jornalista musical se assemelha ao de um gatekeeper, conforme designação de Nunes (2011), que filtra as produções da indústria musical ao fazer a seleção dos artistas e estilos musicais sobre o qual vai escrever ou falar. Assim ele se torna uma figura de referência na área e pode apresentar novos artistas, reverenciar antigos, influenciar gostos e ditar tendências para seus ouvintes.

Torres Silva (2014) afirma que um jornalista musical muitas vezes podese converter em um perito, possibilitando o surgimento de um discurso híbrido, que transita entre o jornalismo e a crítica musical, mesclando um pouco de gosto pessoal ao texto jornalístico. Isso também possibilita a qualificação das músicas e dos artistas, recurso que Edgar utiliza com frequência.

Além da qualificação, o programa é marcado pelo uso dos bordões, que atravessam décadas, e com os quais muitos ouvintes já estão familiarizados ${ }^{10}$, muitos deles relacionados ao dia da semana, como: "Fala o Edgar Augusto na preguiçosa e modorrenta segunda-feira. Dia em que todos lutam para espantar os 'ais' e 'uis' do fim de semana"; "Fala o Edgar Augusto na calorosa quartafeira, dia de abrir a primeira". Outros jargões relacionam-se a quadros no programa, como "Beatlemaníacos empedernidos", que faz referência ao

${ }_{10} \mathrm{Em}$ pesquisa prévia, feita pelas autoras na rede social Facebook, vários jargões foram mencionados pelos ouvintes do programa.

João Pessoa - Brasil | ANO 7 VOL.7 N.1 | JAN./JUN. 2020 | p. 454-473 


\section{ANTLORA}

Jússia VENTURA - Lídia RODARTE - Alda COSTA

Cantinho dos Beatles, assim como o "Do tempo dos titios", que alude às músicas antigas.

É importante destacar que o programa tem um critério de seleção subjetivo, baseado no gosto do produtor e de suas escolhas pessoais, que geralmente, excluem ritmos das periferias de Belém, assim como músicas populares ou massivas. A programação atende mais uma elite cultural.

Nas edições analisadas, observamos um forte caráter saudosista, evidenciado pelo quadro de perguntas sobre Belém de outros tempos, a familiaridade dos jargões repetidos ao longo dos anos e de uma programação estabelecida, cujos sentidos são compartilhados pelos ouvintes. Essa construção familiar evoca a memória e uma série de referenciais simbólicos. Ricoeur (2010), ao falar de construção narrativa histórica, menciona a concordância discordante, que pode aplicar-se a um programa que faz e acompanha a história, mantendo-se no ar há tantos anos.

A concordância discordante é uma tentativa de se conjugarem várias temporalidades e ações subjetivas em uma narrativa comum. Nesse caso, a temporalidade do locutor com as temporalidades dos ouvintes são configuradas de forma comum pela narrativa do programa, que seleciona ações do tempo cronológico, convertendo-as em intriga no tempo configurante, que é o próprio tempo narrativo.

A temporalidade do programa evoca um saudosismo e uma proposta de resgate de memórias da cidade de Belém, porém, apesar disso, essa temporalidade não possui, por si mesma, uma relação de equivalência com o passado. Ela, de fato, constrói uma nova temporalidade, inscrita no tempo do narrado, no qual há uma operação de configuração da intriga (RICOEUR, 2010), com uma seleção de fatores heterogêneos, como eventos, artistas, músicas, lugares e circunstâncias, que não necessariamente possuem ligação no mundo da vida, podendo, inclusive, nunca terem se encontrado ou possuírem qualquer relação histórica, mas que, quando sintetizadas dentro da narrativa, passam a fazer sentido, de maneira lógica e verossímil. 
Esses fatores heterogêneos, ao serem convocados pelo narrador para compor a intriga, conectam-se e tecem uma teia de significados compartilhados entre programa e ouvintes. Assim, a história passa a ser percebida como formando um todo e compartilhando sentidos que possuem os mesmos referenciais simbólicos, refletidos nos jargões, nas expressões, no ordenamento de quadros, repetidos, dia após dia ao longo de décadas, evocando a familiaridade de uma temporalidade narrativa concordante.

A dimensão simbólica da ação está inserida no contexto cultural, faz sentido quando articulada com as normas, os símbolos, os códigos culturais partilhados entre os ouvintes e o locutor. Ela é observada nos quadros que possuem um componente emocional mais forte, que cria vínculo entre as pessoas, pois trabalha com elementos de identificação do público-ouvinte ou que tem interesse pela questão musical. Do mesmo modo, é essa dimensão simbólica, "a mediação e o encontro através do simbólico, a utilização de uma linguagem (um campo de estruturação e de passagem do sentido) que marca a especificidade da relação comunicativa frente a outras formas de relação" (FRANÇA, 2018, p. 171).

Todos esses caracteres, estruturais, simbólicos e temporais, são usados na configuração narrativa e servem de seleção da 'ação que é digna de nota' em detrimento da que pode ser dispensada, que não gera efeito no ouvinte. Essa escolha e o ato de colocar essas ações em ordem são chamados por Ricoeur (2010) de síntese do heterogêneo, que corresponde à síntese que coloca no mesmo contexto, época e cenário, agentes e ações diferentes, de modo que façam sentido para quem ouve a narrativa.

As perguntas, no programa, são conduzidas para rememorar uma capital que viveu um tempo "grandioso" que ficou no passado, deixando de lado a memória de bairros periféricos e as músicas do "subúrbio" paraenses, como tecnobrega, melody e brega. Entretanto, é esse quadro de perguntas que faz os ouvintes interagirem com o programa, tendo em vista que o rádio 


\section{$\hat{A} N[\circ R A$}

Jússia VENTURA - Lídia RODARTE - Alda COSTA

detém "o poder de transmitir uma sensação de cotidianidade através da facilidade de se transpor e recriar a realidade [e, por isso,] confere ao meio uma capacidade de engendrar vínculos com a sua audiência" (KROTH, 2010, p. 146 grifo nosso); a geração desses vínculos remete ao princípio comunicacional de tessitura de laços afetivos (BAITELLO JUNIOR, 2013; VENTURA, 2017) e a uma sociabilidade (SIMMEL, 2006). Isso porque é a oralidade e a conversação do rádio que permitem uma intimidade com o público (JOST, 2010). Ou, então, "a palavra mediada ganha referenciais simbólicos e se insere no sistema das representações entre aquilo que é veiculado e o que é escutado, contexto que envolve o conhecimento de mundo, repertório lexical e semântico, além da experiência estética do ouvinte" (GOMES, s/p).

O rádio tem público rotativo, um público que muda de frequência em busca de estilos musicais que agradem, mas a Feira do Som tem um fenômeno vinculativo, do qual os indivíduos sentem-se parte integrante, como um encontro, um espaço-temporal mediatizado no qual as pessoas reúnem-se. De acordo com a produtora do Programa, Alessandra Caleja, em entrevista ao Portal Cultura ${ }^{11}$, alguns dos ouvintes já interagem com tanta frequência e há tanto tempo, que ela os reconhece pela voz. Já Edgar (PROENÇA, 2019) confessa que tem ouvintes passando de geração em geração.

Por mais pessoal que a memória seja, é construída socialmente (HALBWACHS, 1990) e dividida (PORTELLI, 1997). Para viver em sociedade, o indivíduo cria laços sociais e afetos, busca memórias em comum, afinidades, constrói uma identidade pessoal com interferência coletiva, já que são os grupos sociais que determinam o que deve ser e como deve ser lembrado (HALBWACHS, 1990). Essa construção de sentidos, memórias e vivências coletivas marcam as experiências pessoais de muitos ouvintes. Segundo Ricoeur (2000), não apenas a memória coletiva está associada a uma

${ }^{11}$ Disponível em: <https://www.youtube.com/watch?v=CFoGFZX1Kms>. Acesso em: 22 jul. 2019. 
experiência social, devemos nos questionar se nossas memórias individuais, privadas, não seriam também elaboradas no coletivo, visto que são configuradas, em boa parte, dentro de produtos erigidos pelas estruturas sociais, como a linguagem.

[...] uma recordação diz-se na língua materna, a língua de todos, as nossas recordações mais antigas, as da nossa infância, representam-nos associados à vida dos outros, em família, na escola e na cidade; é muitas vezes juntos que evocamos um passado partilhado (RICOEUR, 2000, s/p.) $)^{12}$.

A linguagem como reflexão ontológica, o compartilhamento de experiências e vivências e o diálogo de consciências estão presentes no processo de encontro com um texto, seja ele lido ou ouvido, e se tornam muito mais complexos quando esse processo, normalmente solitário, torna-se coletivo e dinâmico. Podemos trazer essa experiência para o processo de interação com uma narrativa no rádio, em que há um diálogo de consciências, uma interpretação similar ao que Martino (2010) atribui ao processo de leitura, como uma atividade transformadora dos indivíduos, que modifica ambas as consciências, a que fala e a que escuta, enquanto também produz interpretação, em um processo ativo, provocado, nesse caso, pelo programa, a partir das frases e dos bordões do Edgar, das perguntas e respostas, da construção da narrativa musical.

Nesse processo de produção e troca de sentidos, nem o locutor, nem o ouvinte saem os mesmos depois de se depararem um com o outro, visto que essa troca coloca em diálogo várias singularidades e universos distintos, que ora se permeiam, ora se chocam, ora conflitam, ora convergem, em um discurso mútuo, construído na interação coletiva, inserida no contexto quotidiano da cidade de Belém.

Edgar, ao utilizar em sua narrativa esse hibridismo de gênero, que mescla o jornalista com o fã dos Beatles e conhecedor de música, que faz 12 Texto apresentado em Praga, em outubro de 2000, no Congresso da Federação Internacional da Acção
dos Cristãos para a Abolição da Tortura.

João Pessoa - Brasil | ANO 7 VOL.7 N.1 | JAN./JUN. 2020 | p. 454-473 


\section{ANECRA}

Jússia VENTURA - Lídia RODARTE - Alda COSTA

referência a tempos presente e passado a partir do seu próprio filtro de gosto, trabalha "um jogo de linguagem situado entre a narrativa da história (realista) e a literária (imaginativa)" (MOTTA, 2013, p.200). Esse jogo permite que ele faça desvios textuais da narrativa mais direta do jornalismo e se aproxime do ouvinte, por meio de uma linguagem que, segundo Motta (2013, p. 203) produz "efeitos estéticos de sentido" e, intencionalmente ou não, evoca no ouvinte sentidos poéticos e simbólicos.

Tal movimento investigativo nos fez perceber como a Feira do Som incorporou ou internalizou as mudanças ocorridas na sociedade ao longo de sua existência, levando em conta, conforme França, que os meios não obedecem a diretrizes que estão fora deles, mas "tais diretrizes se encontram dentro dessas práticas, pois o social apenas existe nas diferentes instâncias e ações que compõem a vida social" (FRANÇA, 2018, p. 170).

Ao longo desses anos, a principal transformação do programa foi a relação interativa com o público, pois o locutor passou a falar come não apenas sobre alguém que ouve e dialoga com as produções da Feira. A figura do locutor, segundo Proença (2019), é importante para a construção do vínculo com o público, tendo em vista que uma intimidade foi sendo construída ao longo desses anos. Diariamente, o público escuta a mesma voz e se identifica, inclusive repete junto ao Edgar as frases já conhecidas, criando, assim, conforme escreve Bianco (2018, p. 112), "uma experiência social subjetiva de acolhimento, proximidade, intimidade e conexão com seu entorno de forma peculiar". O programa diário atravessa quase cinco décadas unindo gerações, tanto pela temporalidade, quanto pelo compartilhamento da vivência quotidiana de Belém, sem deixar de fazer jornalismo musical.

\section{Considerações finais}

A Feira do Som foi analisada a partir de uma visada teórica e metodológica de Paes Loureiro e Paul Ricoeur, que apresentam e discutem os conceitos de conversão semiótica e narrativa, respectivamente. Tais elementos nos levam a observar um ajustamento na re-hierarquização de seu significado 
simbólico. Se antes o programa centrava sua narrativa ou produção no locutor e suas preferências de falar para, na atualidade, alterou sua dominância e objetiva falar com, na intenção de estabelecer relações interativas com os ouvintes. Sua inovação se pauta muito mais numa mudança simbólica, que altera a recepção conceitual de sua prática e sua mobilidade de seu lugar na cultura, em que o ouvinte e sua localização adquirem papéis centrais nessa produção. Houve um reforço da narrativa, pela união de vozes diferentes e de novos componentes heterogêneos, quanto da construção de sentido temporal, visto que há uma tentativa de se contribuir com a operação de configuração empreendida por Edgar, o locutor e idealizador do programa.

Por outro lado, e ao mesmo tempo, observamos uma permanência ou linearidade na narrativa da Feira do Som, com poucas transformações do narrador Edgar Augusto, cuja participação é explícita no texto, com comentários, opiniões, digressões, de modo que não é possível demarcar precisamente onde termina o narrador e começa a narrativa.

O programa busca ressignificar seus sentidos, usando signos que estabelecem relações contextuais e culturais com os ouvintes, pois toda mudança material, pensando nos recursos tecnológicos de transformação da realidade dos meios de comunicação e dos indivíduos, é correlata a uma mudança simbólica na sociedade. Nesse sentido, a conversão semiótica operada constitui-se de uma compreensão da realidade de forma dinâmica e concerne ao seu sistema processual de mudanças; além disso, participa da compreensão da realidade dos objetos, que mudam de significação quando são percebidos pelo indivíduo e condicionados pela complexidade das diferentes situações socioculturais que passam a ocupar. Assim explica Loureiro (2007, p. 16): "trata-se, inicialmente, de uma forma de recepção compreensiva e, só depois, transforma-se em condição explicativa". Diante disso, depreendese que percepção e compreensão são fundamentais nesse processo de conversão, considerando a diversidade dinâmica real e simbólica de suas 


\section{ANEORA}

Jússia VENTURA - Lídia RODARTE - Alda COSTA

relações com a realidade que exige uma compreensão também dinâmica e diversa dessas relações.

Portanto, o programa Feira do Som, mesmo abrigado numa emissora de rádio tradicional, de caráter educativo, conseguiu, em quase 50 anos de existência, estabelecer uma relação de inovação frente às novas modalidades de rádio e de programação. Acreditamos que essa longevidade se configura a partir de alguns elementos centrais, entre eles: a) a informação na valorização do conteúdo musical, que se constitui num diferencial, pois não é a música pela música, mas uma produção que tem história e contexto cultural e social; b) os produtos da comunicação pública têm possibilidades de construção de conteúdo e de público para consumo e modalidades específicas, sem a preocupação com o percentual de audiência; c) o programa se estabelece como importante espaço de divulgação e comunicação dos artistas locais; d) a programação inova ao mesclar jornalismo cultural e musical, assim como quando brinca com a imaginação criadora e produtiva, assentada em modelos e paradigmas tradicionais, como a própria linguagem; e) a criação da possibilidade de construção de uma memória social a partir dos quadros existentes, estabelecendo relações de identificação com o público local; e f) a conexão de uma experiência estética entre a cena musical e a cidade de Belém, resultando na criação de uma relação simbólica com a cenarização, a partir da linguagem, com o imaginário do ouvinte.

Apesar da sonoridade existente na cidade de Belém, o programa é alicerçado num critério de seleção subjetivo, baseado no gosto do produtor e de suas escolhas, que excluem ritmos latentes e que marcam a vida social das periferias belenenses, como as aparelhagens e os tecnobregas. Apesar de 0 programa ser vendido como Feira, com diversidade musical, o som do "subúrbio" ainda está ausente. A programação faz parte de uma elite cultural, mesmo que o discurso proponha a ideia de uma mestiçagem musical, com incorporação de sons populares e eruditos, mas esse popular não é periférico, tampouco massivo. 


\section{Referências}

BAITELLO JUNIOR, Norval. As núpcias entre o nada e a máquina. As notas sobre a era da imagem em lugar do corpo. CISC. 2013. Disponível em: <http://www.cisc.org.br/portal/pt/biblioteca/viewcategory/7-baitellojuniornorval.html>. Acesso em: 30 jun. 2018.

BAL, Mike. Teoría de la narrativa: una introducción a la narratología. Tradução de Javier Franco. Madrid: Cátedra, 1985. BIANCO, Nelia Del. Rádio e memória do cotidiano. Revista Brasileira de História da Mídia, v. 7, n. 1, p. 11-123, jan./jun. 2018. CARVALHO, Carlos Alberto de. A tríplice mimese de Paul Ricoeur como fundamento para o processo de mediação jornalística. Trabalho apresentado ao Grupo de Trabalho "Estudos de Jornalismo". ENCONTRO DA COMPÓS, 19., Rio de Janeiro: PUC, jun. 2010.

CASTRO, Fábio Fonseca de. Entre o mito e a fronteira: estudo sobre a figuração da Amazônia na produção artística contemporânea de Belém. Belém: Labor Editorial, 2011.

CASTRO, Fábio Fonseca de. Comunicação, identidade e TV pública no Pará. Em Questão, Porto Alegre, v. 18, n. 2, p. 149-167, jul./dez. 2012. COSTA, Alda Cristina; MEDEIROS, Rosana. Rádio Cultura FM: 30 anos de comunicação pública na Amazônia paraense. Revista Brasileira de História da Mídia (RBHM), v. 4, n. 1, jan./ jun. 2015. COSTA, Antônio Maurício Dias da. Cidade dos sonoros e dos cantores: estudo sobre a Era do Rádio a partir da capital paraense. Belém: Imprensa Oficial do Estado, 2015.

COSTA, Vânia Maria Torres. 'À sombra da floresta': os sujeitos amazônicos entre estereótipo, invisibilidade e colonialidade no telejornalismo da Rede Globo. 2011. 290 f. Tese (Doutorado em Comunicação Social) - Instituto de Artes e Comunicação Social, Universidade Federal Fluminense, Rio de Janeiro, 2011.

DURAND, Gilbert. As Estruturas Antropológicas do Imaginário. São Paulo, Martins Fontes, 2001.

DUTRA, Manuel Sena. A natureza da mídia: os discursos da TV sobre a Amazônia, a biodiversidade, os povos da floresta. São Paulo: Annablume, 2009.

FRANÇA, Vera Veiga. Sociabilidade: implicação do conceito nos estudos da comunicação. In: Produção de sentidos e tecnologia: estudos contemporâneos em comunicação. Flávia de Almeida Moura et.al (orgs). São Luís: EDUFMA, 2018.

FUNTELPA. Fundação de Telecomunicações do Pará: 30 anos construindo a história da comunicação pública no Pará. Belém: Funtelpa, 2007.

GOMES, Adriano Lopes. 0 rádio e a experiência estética na constituição do ouvinte. Disponível em: 


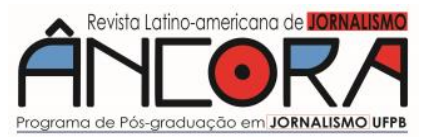

Jússia VENTURA - Lídia RODARTE - Alda COSTA

<http://www.bocc.ubi.pt/pag/gomes-adriano-radio-experienciaestetica.pdf >. Acesso em: jul. 2019.

HALBWACHS, Maurice. A memória coletiva. São Paulo: Vértice, 1990. JOST, François. Compreender a televisão. Porto Alegre: Sulina, 2010. $\mathrm{KROTH}$, Maicon E. Contratos de leitura: narrativas do cotidiano como estratégia de captura da recepção no rádio. In: FERRARETTO, Luiz Artur(Org.). E o rádio?: novos horizontes midiáticos. Porto Alegre: Edipucrs, 2010, p. $142-156$.

LOUREIRO, João de Jesus Paes. A conversão semiótica: na arte e na cultura. Belém: EDUFPA, 2007 (Edição trilíngue).

LOUREIRO, João de Jesus Paes. Cultura Amazônica: uma poética do imaginário. Belém: Cejup,1995.

MARTINO, Luís Mauro Sá. Comunicação e identidade: quem você pensa que é?. São Paulo: Paulus, 2010 (Coleção Comunicação).

MOTTA, Luiz Gonzaga. Análise crítica da narrativa. Brasília: Editora Universidade de Brasília, 2013.

NUNES, Pedro. Os jornalistas de música e a indústria musical: entre 0 gatekeeping e o "cheerleading". Trajectos, Lisboa, v. 18, p. 53-69, 2011. PORTELLI, Alessandro. Tentando aprender um pouquinho: algumas reflexões sobre a ética na História Oral. Projeto História 15. São Paulo, 1997. PROENÇA, Edgar Augusto. Entrevista concedida a uma das pesquisadoras. Belém, fev. 2017.

PROENÇA, Edgar Augusto. Entrevista concedida a uma das pesquisadoras. Belém, fev. 2019.

RIBEIRO, Emiliana Pomariso. Micronarrativas afetivas: o tocar pelo invisível para uma comunicação visível. In: CONGRESSO BRASILEIRO DE CIÊNCIAS DA COMUNICAÇÃO, 36., 2013, Manaus. Anais... São Paulo: Intercom, 2013. p. 1-15.

RICOEUR, Paul. Identidade frágil: respeito pelo outro e identidade cultural. In: Les droits la personne en question. Europa: FIACAT, 2000. RICOEUR, Paul.Tempo e narrativa 1: A intriga e a narrativa histórica. Trad. Claudia Berliner. São Paulo: WMF Martins Fontes, 2010.

SIMMEL, Georg. Questões fundamentais de sociologia. Rio de Janeiro: Zahar, 2006.

TORRES SILVA, Marisa. Jornalismo musical: estratégias enunciativas e retóricas. Contributos para uma análise discursiva. Revista Comunicação Midiática, v. 9, n. 1, p. 12-35, jan./abr. 2014.

VENTURA, Jússia Carvalho da Silva. Cartografia sensível: televisão, interação e afetividade entre o publico e o programa Sem Censura Pará. 2017, 132p. Dissertação (Mestrado em Ciências da Comunicação) - Programa de Pós-Graduação Comunicação, Cultura e Amazônia, Universidade Federal do Pará, Belém, 2017. 